\title{
DESIGN AND PERFORMANCE ANALYSIS OF BAND PASS FILTER USING BLACKMAN, HAMMING AND KAISER WINDOWS
}

\author{
Ghulam Ahmad Raza ${ }^{1}$, Md. Jafir Alam², Md. Nasim Ansari ${ }^{3}$ \\ ${ }^{1}$ Assistant Professor, Department of Electronics \& Communication Engineering, Siwan Engineering \& Technical \\ Institute, Siwan, Bihar, India \\ ${ }^{2}$ Assistant Professor, Department of Electronics \& Communication Engineering, Siwan Engineering \& Technical \\ Institute, Siwan, Bihar, India \\ ${ }^{3}$ Assistant Professor, Department of Electronics \& Communication Engineering, Siwan Engineering \& Technical \\ Institute, Siwan, Bihar, India
}

\begin{abstract}
In this paper bandpass filter has been designed and simulated using different windows techniques. Blackman, Hamming and Kaiser Windows techniques are used for design of bandpass filters using matlabs. The performances of all designs have been compared in terms of sidelobe attenuation and mainlobe width. The simulated result shows that Blackman window gives maximum mainlobe width as compared to Hamming and Kaiser Windows. The result also shows that increasing the Kaiser Window parameter Beta widens the mainlobe and decreases the amplitude of sidelobes.
\end{abstract}

Keywords: Blackman Window, DSP, FIR Digital Filter, Kaiser Window and Hamming Window

\section{INTRODUCTION}

DSP is used in different areas such as image processing, spectrum analysis, speech synthesis, robotic vision, sonar processing, facsimile, digital cameras, data communication etc. DSP system can be programmed and reprogrammed without changing in hardware. It has many advantages such as guaranteed accuracy, perfect reproducibility, greater flexibility and better performance. The signal used in DSP is derived from analog signal which have sampled at certain interval to convert into digital signal [1]. Digital filters are important class of Linear time invariant DSP system design to modify the frequency characteristics of the input signal $\mathrm{x}(\mathrm{n})$ to meet certain specific design requirements. Digital filters have emerged as a strong option for removing noise, shaping spectrum and minimizing inter-symbol interference (ISI) in communication architectures [2]. Digital filters are classified into Finite Impulse response (FIR) and Infinite Impulse Response (IIR) filters. The FIR has an impulse response $h(n)$ of finite duration, defined over the interval $0 \leq$ $\mathrm{m} \leq \mathrm{M}$, has finite number of terms,

$$
\mathrm{y}(\mathrm{n})=\sum_{m=0}^{M} \mathrm{~h}(\mathrm{~m}) \cdot \mathrm{x}(\mathrm{n}-\mathrm{M})
$$

An IIR filter has an impulse response $h(n)$ of infinite duration, defined over the infinite interval $0 \leq n \leq \infty$, now infinite number of terms are given by

$$
y(n)=\sum_{m=0}^{\infty} h(m) \cdot x(n-M)
$$

\section{FIR DESIGN METHODS}

Window Technique and Optimal Filter Design Method are used for designing of filters. The simplest method of FIR filter design is the window method. This method begins with an ideal desired frequency response which is represented as

$$
\mathrm{H}_{\mathrm{d}}(\mathrm{w})=\sum_{n=0}^{\infty} h_{d}(\mathrm{n}) e^{-j w n}
$$

Where

$$
\mathrm{h}_{\mathrm{d}}(\mathrm{n})=\frac{1}{2 \pi} \int_{-\pi}^{\pi} H_{\mathrm{d}}(\mathrm{w}) \mathrm{e}^{\mathrm{jwn}} \mathrm{dw}
$$

Some of windows used are Blackman Window, BlackmanHaris window, Bohman window, Chebyshew window, Flat Top window, Gaussian window, Hamming window, Hanning window, Nuttall window, Kaiser Window, Rectangular window, Taylor window, Triangular window and Tukey window.

The following equation defines the Blackman window of length $\mathrm{N}$ [3].

$$
\begin{gathered}
w(n)=0.42-0.5 \cos (2 \pi n /(N-1))+0.08 \cos (4 \pi n /(N-1)) \\
, 0 \leq n \leq M-1
\end{gathered}
$$

Where $\mathrm{M}$ is $\mathrm{N} / 2$ for $\mathrm{N}$ even and $(\mathrm{N}+1) / 2$ for $\mathrm{N}$ odd

To eliminate the some pass band and stop band ripples, Hamming window technique is used [4]. The coefficients of a Hamming window are computed from (6)

$$
w(n)=0.54-0.46 \cos \left(2 \pi \frac{n}{N}\right), 0 \leq n \leq N
$$


Kaiser window has an adjustable shape parameter that allow the window to achieve any desire value of ripple or attenuation. Kaiser window is unique that it has near optimum performance, in the sense of minimizing the sidelobe energy of the window as well as having the simplest implementation [5]. Kaiser window depends on two parameters, $\mathrm{N}$ and the shape parameter $\alpha$. The equation of Kaiser Window is expressed in (7).

$w(n)=\frac{I_{0}\left(\alpha \sqrt{1-(n-M)^{2} / M^{2}}\right.}{I_{0}(\alpha)}$

Kaiser window is also defined in terms of $\beta$, where $\beta$ is the Kaiser Window parameter that affects the sidelobe attenuation of the Fourier transform of the window [6].

The Kaiser window that design an FIR filter with sidelobe attenuation of $\alpha \mathrm{dB}$ is expressed as

$\beta=\left\{\begin{array}{cc}0.1102(\alpha-8.7), & \alpha>50 \\ \left.0.5842(\alpha-21)^{0.4}\right) & \\ +0.07886(\alpha-21), & 50 \geq \alpha \geq 21 \\ 0, & \alpha<21\end{array}\right.$

\section{DESIGN SIMULATIONS}

Table 1 shows the parameter specifications to design the bandpass FIR Filter using Blackman, Hamming and Kaiser Windows.

\subsection{Parameter Specification}

\begin{tabular}{|l|l|}
\hline Parameter & Values \\
\hline Sampling Frequency & $48000 \mathrm{~Hz}$ \\
\hline Cutoff Frequency & $10800 \mathrm{~Hz}$ \\
\hline Order & 30 \\
\hline$\beta$ & $\beta=0.5,2,5$ (For Kaiser Window) \\
\hline
\end{tabular}

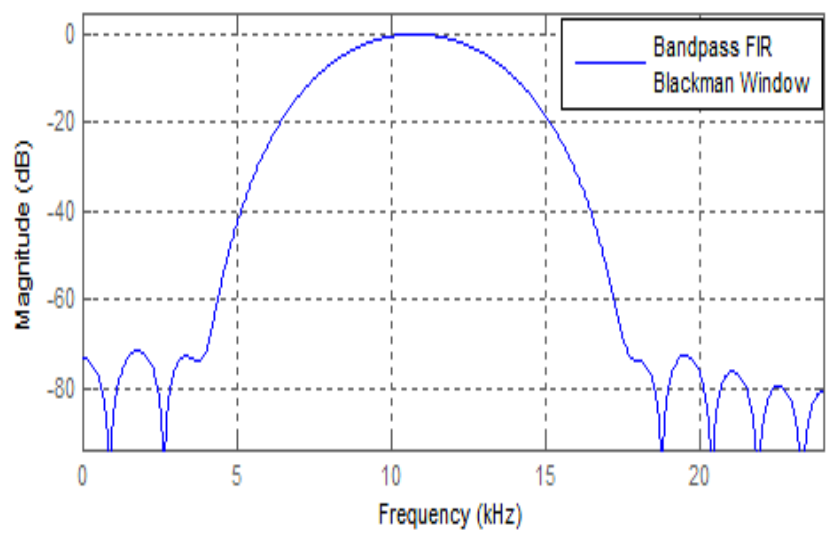

Fig 1: Bandpass FIR filter using Blackman window

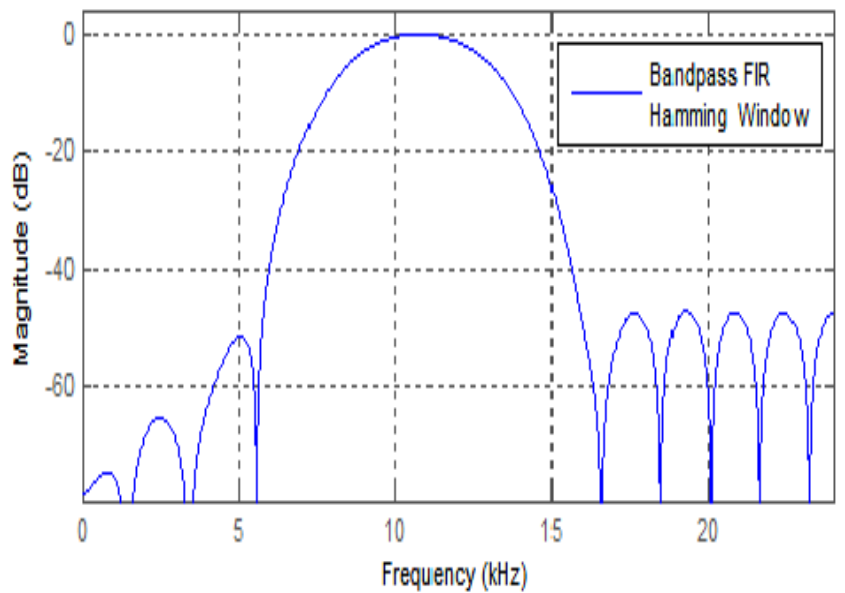

Fig 2: Bandpass FIR filter using Hamming window

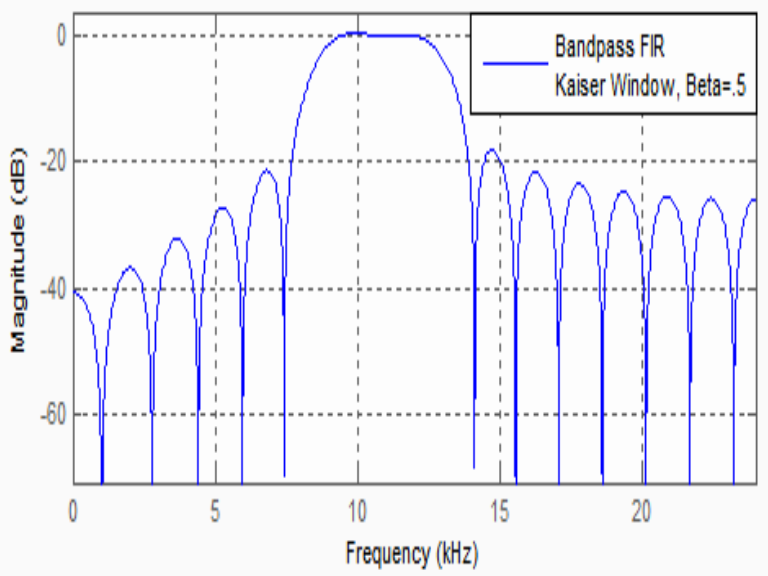

Fig 3: Bandpass FIR filter using Kaiser Window $(\beta=0.5)$

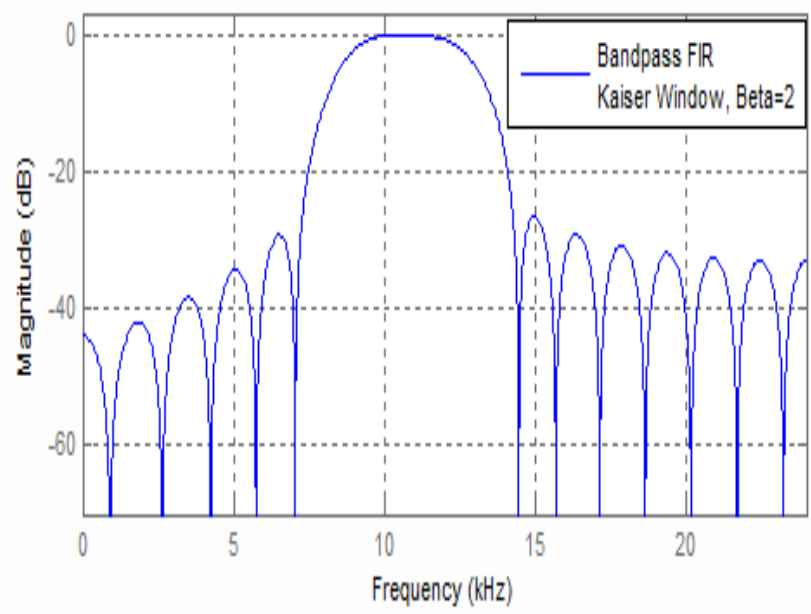

Fig 4: Bandpass FIR filter using Kaiser Window $(\beta=2)$ 


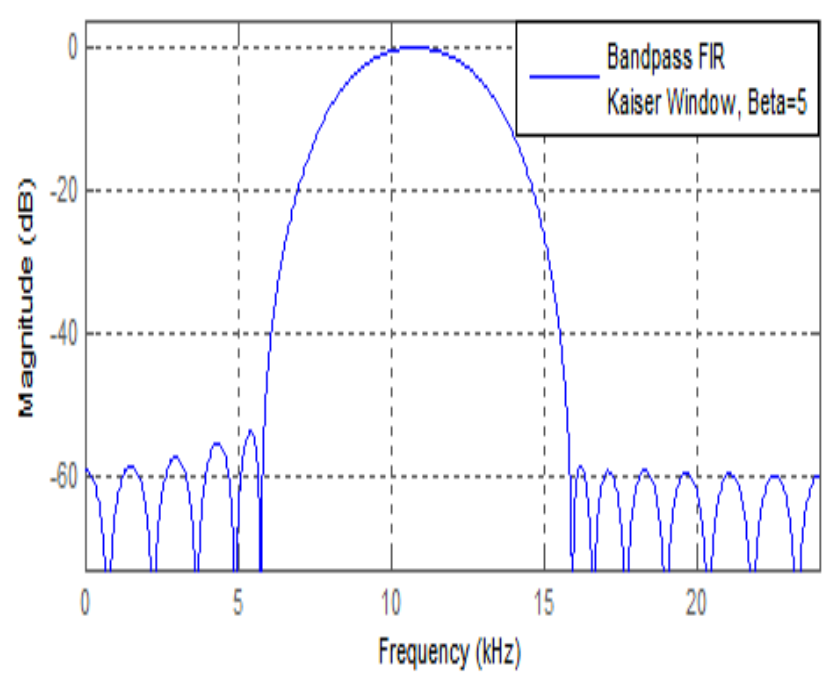

Fig 5: Bandpass FIR filter using Kaiser Window $(\beta=5)$

Figure $1 \& 2$ show the magnitude and frequency response of Bandpass FIR filter using Blackman and Hamming window. Figure 3, 4, and 5 show Kaiser Window at $\beta=0.5, \beta=2$ and $\beta=5$ respectively.

\section{COMPARATIVE ANALYSIS}

Blackman, Hamming and Kaiser Windows techniques are used for design of bandpass FIR filter and compared these three windows. Figure 6 shows three windows in time domain. Bold line of the figure show Blackman window, dotted line show Hamming window and dashed line show Kaiser window $(\beta=0.5)$. Blackman window is narrower than Hamming and Kaiser Windows. Table 2 shows the comparison of these three windows in terms of relative sidelobe attenuation and mainlobe width. The mainlobe width is maximum of Blackman Window than the Hamming and Kaiser windows.

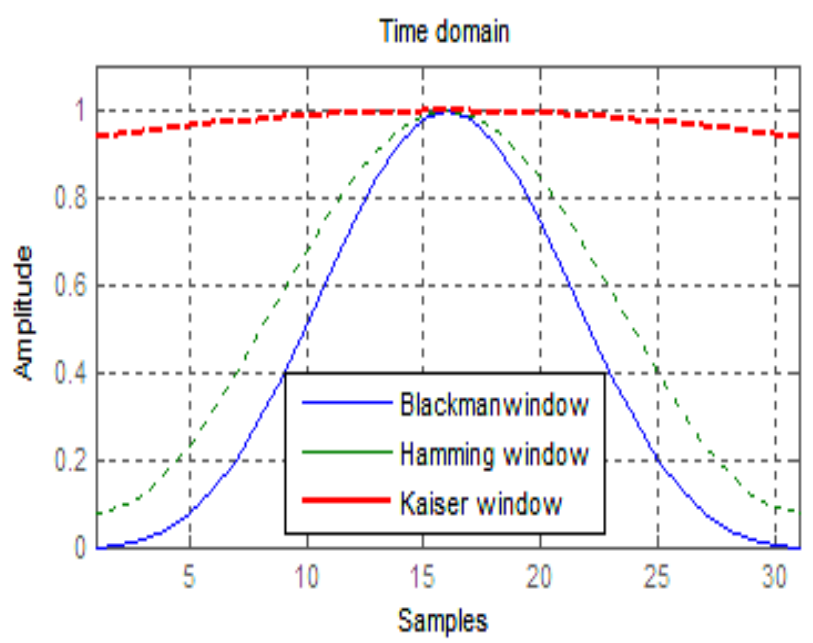

Fig 6: Time domain of Blackman, Hamming and Kaiser Window $(\beta=0.5)$
Table 2: Matlab simulated result of Rectangular, Hamming and Kaiser Windows.

\begin{tabular}{|l|l|l|}
\hline Windows & $\begin{array}{l}\text { Relative Sidelobe } \\
\text { attenuation }\end{array}$ & $\begin{array}{l}\text { Main lobe width } \\
(-3 \mathrm{~dB})\end{array}$ \\
\hline Blackman & $-58.2 \mathrm{~dB}$ & 0.10938 \\
\hline Hamming & $-41.7 \mathrm{~dB}$ & 0.085938 \\
\hline Kaiser $(\beta=0.5)$ & $-13.6 \mathrm{~dB}$ & 0.054688 \\
\hline Kaiser $(\beta=0.2)$ & $-18.9 \mathrm{~dB}$ & 0.0625 \\
\hline Kaiser $(\beta=5)$ & $-37.8 \mathrm{~dB}$ & 0.085938 \\
\hline
\end{tabular}

\section{CONCLUSIONS}

In this paper bandpass FIR filter has been designed and simulated using Blackman, Hamming and Kaiser Windows techniques at sampling frequency $48000 \mathrm{~Hz}$, cutoff frequency $10800 \mathrm{~Hz}$ and order 30. Bandpass filter has been designed for the different value of Kaiser Window parameter $\beta$. It has been compared relative sidelobe attenuation and mainlobe width of these three windows. Blackman window is narrower than Hamming and Kaiser Windows. The simulated result show that increasing the value of Kaiser Window parameter $\beta$ widens the mainlobe and decrease the amplitude of sidelobes that is increases the attenuation.

\section{ACKNOWLEDGEMENTS}

Authors would like to thank the Hon'ble Chairman, Dr. Md. Shahabuddin, Secretary, members of the management and Director, Siwan Engineering \& Technical Institute, Siwan, India. Authors also would like to thank the DirectorIn-Charge, Dr. Noruddin Ansari, for his constant inspirations and support throughout this research work.

\section{REFERENCES}

[1]. Emmanuel C. Ifeacher, Barrie W.Jervis "Digital Signal Processing”, Second Edition, Pearson Publication, pp. 0240, 2004

[2]. Keshab.K.Parhi, "VLSI Digital Signal Processing Systems Design and Implementation". First edition, A Wiley-Interscience Publication, pp. 10-50, 1999

[3]. Oppenheim, A.V, and R.W. Schafer. "Discrete - Time Signal Processing”. Upper Saddle River, NJ: Prentice Hall, pp.468-471, 1999.

[4]. F. J. Harris, "On the use of Windows for Harmonic Analysis with the Discrete Fourier Transform”, Proc. IEEE, 1978

[5]. Sophocles J.Orfanidis, "Introduction to Signal Processing” Prentice Hall, First Edition, pp.532-558, 1996

[6]. Kaiser, J.F, "Nonrecursive Digital Filter Design Using the IO-Sinh Window Function", Proc. IEEE symp. Circuit and Systems, pp.20-23, 1974 


\section{BIOGRAPHIES}

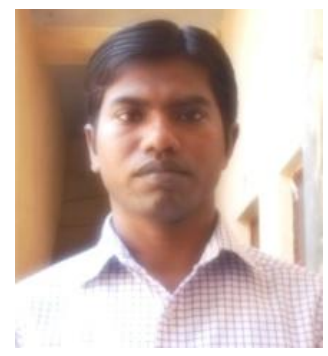

Ghulam Ahmad Raza received the Bachelors of Technology degree in Electronics \& Communication Engineering from Maulana Azad College of Engineering \& Technology Patna, India in 2009. $\mathrm{He}$ is pursuing M.E in Electronics \& Communication Engineering from National Institute of Technical

Teachers' Training \& Research, Ministry of Human Resource Development, Panjab Univsrsity, Chandigarh, India.

$\mathrm{He}$ is an Assistant Professor in the Department of Electronics \& Communication Engineering, Siwan Engineering \& Technical Institute Siwan, Bihar, India. His current research and teaching interests are in DSP, Communication System and Microwave Engineering.

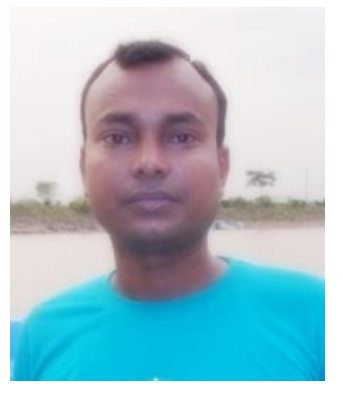

Md. Jafir Alam received the Bachelors of Technology degree in Electronics \& Communication Engineering from Maulana Azad College of Engineering \& Technology Patna, India in 2007. $\mathrm{He}$ is pursuing M.E in Electronics and Communication Engineering from National Institute of Technical Teachers' Training \& Research, Ministry of Human Resource Development, Panjab Univsrsity, Chandigarh, India.

$\mathrm{He}$ is an Assistant Professor in the Department of Electronics \& Communication Engineering, Siwan Engineering \& Technical Institute Siwan, Bihar, India. His current research and teaching interests are in Signal and Systems, Digital Communication and Digital Electronics.

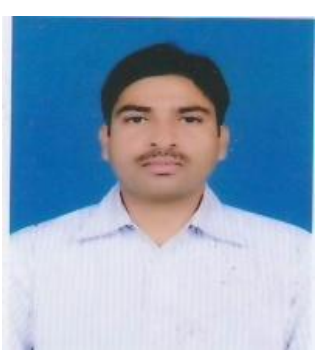

Md. Nasim Ansari received the Bachelors of Technology degree in Electronics \& Communication Engineering from Maulana Azad College of Engineering \& Technology Patna, India in 2007. $\mathrm{He}$ is pursuing M.E in Electronics \& Communication Engineering from National Institute of Technical

Teachers' Training \& Research, Ministry of Human Resource Development, Panjab Univsrsity, Chandigarh, India.

$\mathrm{He}$ is an Assistant Professor in the Department of Electronics \& Communication Engineering, Siwan Engineering \& Technical Institute Siwan, Bihar, India. His current research and teaching interests are in DSP and Wireless Mobile Communication. 